\title{
Basketbolun Değişen Oyun Yapısı: NBA ve EuroLeague Örnekleri
}

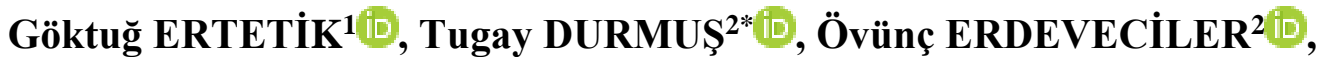 Gülfem ERSÖZ $Z^{2}$}

\author{
${ }^{1}$ Kastamonu Üniversitesi, Kastamonu, Türkiye \\ ${ }^{2}$ Ankara Üniversitesi, Ankara, Türkiye
}

Orijinal Makale

Gönderi Tarihi: 06.04.2021
Kabul Tarihi: 30.06 .2021
DOI: 10.47778/ejsse.907049

Online Yayın: 30.06.2021

\section{Öz}

Basketbol, küresel olarak en yaygın sporlardan birisidir ve bununla birlikte dünyada iki organizasyon ön plana çıkmaktadır: Amerikan Ulusal Basketbol Ligi (NBA) ve Avrupa Ligi (EuroLeague). Takım sporlarında performans analizi, antrenman ve müsabaka sürecine ilişkin verilere erişim kolaylığı ile son on yılda giderek hızlanmıştır. Basketbolun değişen oyun yapısı ve bazı parametrelerin basketbolun oyun stiline etkileri konusunda çalışmalar bulunmaktadır. Sayı, ortalama atış denemesi ve ortalama isabetli atış, ortalama üç sayılık atı̧̧ denemesi ve ortalama isabetli üç sayı, asist, ribaunt, blok, top çalma, top kaybı parametreleri değerlendirilerek oyunun yapısındaki değişikliklerin neler olduğunu belirlemek bu çalışmanın amacı olarak belirlenmiştir. Çalışma, 2002 - 2020 yılları arasında Amerikan Ulusal Basketbol Ligi (NBA) ve Avrupa Basketbol Ligi (EuroLeague) normal sezonlarında oynanan müsabakaları kapsamaktadır. Takımların maç başına sayıları, atış denemeleri ve isabetli atış sayısı, takımların maç başına üç sayılık atış denemeleri ve isabetli atış sayısı, ribaund, asist, top çalma, top kaybı ve blok ortalamaları parametreleri gruplandırılarak değerlendirilmiştir. Yapılan analizlerde EuroLeague ve NBA'de sezonlar ilerledikçe en çarpıcı değişimlerin maç başına sayı denemesi, atılan sayı, maç başına üç sayılık atış denemesi ve isabetli üç sayılık atışlarda meydana geldiği tespit edilmiştir. Oyun içerisinde meydana gelen sürekli değişim ve gelişim göz önüne alındığında yapılan çalışmaların güncellenmesi ve farklı istatistiksel yöntemler/yaklaşımlar kullanılarak her iki ligin de analiz edilmesine ihtiyaç duyulmaktadır.

Anahtar kelimeler: Basketbol, müsabaka analizi, basketbolda oyun sistemleri.

\section{The Changing Game Structure of Basketball: Examples of NBA and EuroLeague}

\begin{abstract}
Basketball is one of the most widespread sports globally, and with this, two organizations stand out in the world: NBA (National Basketball Association) and EuroLeague (Europa League). There are studies about the changing game structure of basketball and the effects of some parameters on the playing style of basketball. This study includes games played in National Basketball Association (NBA) and European Basketball League (EuroLeague) regular seasons between 2002 and 2020. The points per game, shot attempts/made, three-point attempts/made, rebounds, assists, steals, turnovers, and block averages of the teams have all been grouped and analyzed. Since there are differences between the two leagues in terms of game time and game rules, the change and comparison of these parameters over the years have been made separately for the two leagues. As a result of the analysis, it was found that the most significant changes occurred in the number of shots made per game, the points scored, the average three-point shot attempts per game, and the successful three-point shot attempts as the seasons progressed in the EuroLeague and NBA. The biggest changes in the statistical categories considered within the scope of the study occurred in the three-point attempts and the three-point shooting rate. There are many studies in the literature that have examined both leagues with different parameters and statistical methods. However, considering the continuous changes and developments occurring in the game, it is necessary to update the studies and analyze both leagues by using different statistical methods/approaches.
\end{abstract}

Keywords: Basketball, match analysis, basketball game structures.

\footnotetext{
** Sorumlu Yazar: Tugay DURMUŞ, E-posta: tugaydurmus@ankara.edu.tr
} 


\section{GİRIŞ}

Basketbol oyununun herhangi bir takım için iki basit hedefi vardır. Takımların amacı çeşitli hücum yöntemlerini kullanarak sayı üretmek ve uygun savunma stratejileriyle rakiplerinin sayı bulmasının önüne geçmektir. Müsabaka sonucunda ise daha fazla sayı üreten takım karşılaşmayı kazanır (Fichman ve O'Brien, 2017). Basketbol, dünya çapında en çok katılımcıya sahip spor branşlarından birisidir. Ulusal ve uluslararası düzeylerde bir çok organizasyon düzenlenmektedir ve bunlardan ikisi ön plana çıkmaktadır: Amerikan Ulusal Basketbol Ligi (NBA) ve Avrupa Ligi (EuroLeague). NBA, dünyadaki en rekabetçi basketbol ligidir ve yaklaşık 24 hafta süren normal sezonda takımlar 82'şer maça çıkmaktadırlar (Paulauskas vd., 2018). Doğu ve Batı olarak iki konferansa ayrılmış 30 takımın mücadele ettiği ligde normal sezonun ardından konferanslarında ilk 8'de yer alan takımlar Playoff'lara katılmaya hak kazanmakta, yedi maç üzerinden oynanan Playoff serilerinin sonucunda ise Doğu ve Batı konferansı şampiyonlarının NBA şampiyonluğu için karşılaştı̆̆ yedi maçlık NBA finalleri oynanmaktadır (NBA). EuroLeague'de ise 18 takımlı, 34 maç süren bir normal sezonun ardından ilk 8 takım Playoff'a katılmaya hak kazanır. Beş maç üzerinden oynanan Play off serilerinin ardından eşleşmelerini kazanan dört takım Final Four (dörtlü final) için hak elde etmektedir. Çapraz eşleşme ve tek maçlı eleme usulüne göre oynanan maçların ardından iki maç kazanan takım EuroLeague sezonunu şampiyon olarak tamamlar (EuroLeague).

Basketbolda, oyunun oynanış biçimini etkilemek için kural değişiklikleri sıklıkla yapılmıştır. Örneğin, 1954'te NBA'de şut saatinin eklenmesiyle; oyun temposu yükselmiş, skorlar artmış ve oyunu duraklatma taktikleri sona ermiştir. Bu kuralın ardından, 1954 sezonunda maç başına 79,5 olan sayı ortalaması 1955 sezonunda maç başına 93,1 sayıya ulaşmıştır. Kuralların değişimi ile beş yıl içinde takımlar farklı ve daha hızlı bir oyun stili yaratmışlardır ve nitekim beş sezon içinde ise artık ligdeki her takım maç başına 100 sayı ve üzeri sayı ortalaması yakalamıştır (Fichman ve O’Brien, 2017). NBA basketbol tarihinde kurallardaki en çarpıcı değişikliklerden birinin 19791980 sezonunda üç sayılık atışın oyuna dahil edilmesi olduğu söylenebilir. O yıllarda yapılan bu değişiklik etkisini hemen gösterememiş olsa da günümüz basketbolunda üç sayı çizgisinin oyun stratejilerini etkileyen önemli bir unsur olduğunu söylemek mümkündür (Arias vd., 2009; Nourayi, 2019).

2010-2011 basketbol sezonu başında FIBA tarafından getirilen kural değişiklikleri ile FIBA' ya bağlı bütün federasyonlar ve organizasyonlar basketbolu yeni kuralları ile oynamaya başlamıştır. Bu kurallar; boyalı alanda yer alan yarım daire, üç sayı çizgisinin çemberden 6,75 metreye geriletilmesi ve 24 saniye hücum süresinin ne şekilde ve ne zaman yenileneceği gibi oyunun gidişatını önemli ölçüde etkileyebilecek değişiklikleri kapsamıştır. Kural değişikliklerinin doğal bir getirisi olarak da iki sayılık ve üç sayılık atışların miktar ve verimliliklerinde değişimler meydana gelmesi beklenmiştir (Strumbelj vd., 2013). 
Ertetik, G., Durmuş, T., Erdeveciler, Ö. ve Ersöz, G. (2021). Basketbolun değişen yapısı : NBA ve Euroleague örnekleri. Avrasya Spor Bilimleri ve Ĕgitim Dergisi, 3(1), 81-95.

Literatürde, yıllar içerisinde basketbolun değişen oyun yapısı ve birtakım parametrelerin basketbolun oynanış biçiminde yarattığ 1 etkilere dair çalışmalar mevcuttur. İspanya Basketbol Ligi'nde yapılan bir çalışmada, başarılı takımların başarısız takımlara oranla daha fazla asist yaptığı, daha iyi serbest atış attı̆̆ı, daha az faul yaptı̆̆ 1 ve daha fazla savunma ribaundu aldığ belirtilmiştir (Ibáñez vd., 2008). Avrupa basketbolu ile ilgili olarak yapılan bazı çalışmalarda, takımların performansının öncelikle iki sayılık atışlara ve savunma ribauntlarına bağlı olduğu belirtilmektedir. Yakın skorlar ile geçen maçlarda fauller ve serbest atışların oyun sonucunun belirlenmesinde, sayı farkının çok olduğu maçlara göre daha fazla önem taşıdığ aktarılmıştır (Karipidis vd., 2001; Sampaio ve Janeira, 2003). Strumbelj vd., (2013) EuroLeague'deki kural değişikliklerinin oyun üzerine olan etkilerini araştırmışlardır. 2001 ve 2010 yılları arasında EuroLeague'de oynanan maçlar çalışma kapsamında incelenmiştir. Yıllar içerisinde, kullanılan üç sayılık atışlarda yükseliş, iki sayılık atışların ise düşüş yönelimi bildirilmiş ve anlamlı bir fark bulunmuştur. Öte yandan fauller ve serbest atış sayılarında anlamlı bir azalma, blok ve asist sayılarında ise anlamlı bir artış olduğu bildirilmiştir. NBA ve EuroLeague takımlarının hücum stillerinin karşılaştırdığı bir çalışmada ise NBA takımlarını, EuroLeague takımlarından ayıran en bariz özelliğin boyalı alan hücumu olduğu belirtilmiştir (Mavridis vd., 2017). Çalışmada ayrıca, EuroLeague takımlarının hücumu yerden pas (bounce pas) ile başlatırken NBA takımlarının baş üstü pası daha fazla kullandıklarına dikkat çekilmiş ve bu farkın NBA oyuncularının fiziksel özellikleri (boy, çeviklik) ile ilişkili olabileceği vurgusu yapılmıştır (Courel-Ibáñez vd., 2016).

Son on yılda, antrenman ve yarışma sürecine ilişkin verilere ulaşımın da kolaylaşmasıyla takım sporlarında performans analizleri giderek artmıştır (Drust, 2010; Franks ve Hughes, 2007). Dünyanın farklı yerlerinde farklı taktik ve yaklaşımları basketbol sahalarında görmek mümkündür. 1990'lı yılların sonuna dek oynanan "yavaş ve tahmin edilebilir" olarak nitelendirilen (Dean, 2001) oyun sistemleri yerini; iç ve diş dengesinin kurulduğu (Ibáñez vd., 2018), bireysel hücum stillerinin ön plana çıktığı (Scanlan vd., 2018) ve oyuncuların pozisyonlarının görevleri dışında roller üstlendiği (Mateus vd., 2018) bir basketbol stiline bırakmıştır.

Basketbol, sürekli gelişen ve taktik stratejilerin oyun sonucuna doğrudan etki ettiği bir spordur. Dünyanın önde gelen basketbol liglerindeki oyun yapısının ve uygulanan oyun stratejilerinin takibi basketbol antrenörleri için önem taşımaktadır. Bu çalışmada, sayı, ortalama atış denemesi ve ortalama isabetli atış, ortalama üç sayılık atış denemesi ve ortalama isabetli üç sayı, asist, ribaunt, blok, top çalma, top kaybı kategorileri incelenerek en üst rekabet seviyelerinde basketbolun seneler içindeki değişimi ele alınmıştır. Bu sayede farklı seviyelerdeki antrenörler, oyunun oynanış biçimi hakkında fikir sahibi olabilir ve mevcut oyun sistemlerinde düzenlemelere gidebilir. Oyunun oynanış biçimindeki yönelim göz önüne alınarak alt yapı oyuncularının teknik ve taktik becerileri bu çerçevede geliştirilmeye çalışılabilir. Ayrıca bu çalışma, araştırmacılar için basketbolun oynanış biçimindeki değişimleri raporlayan Türkçe dilindeki bir kaynak olarak da faydalı olabilir. $\mathrm{Bu}$ çalışmanın amacı, NBA ve EuroLeague takımlarının 2002-2020 yılları arasındaki müsabakalarının sayı, atış denemeleri ve isabetli atış sayısı, takımların maç başına üç sayılık atış 
Ertetik, G., Durmuş, T., Erdeveciler, Ö. ve Ersöz, G. (2021). Basketbolun değişen yapısı : NBA ve Euroleague örnekleri. Avrasya Spor Bilimleri ve Eğitim Dergisi, 3(1), 81-95.

denemeleri ve isabetli atı̧̧ sayısı, ribaund, asist, top çalma, top kaybı ve blok parametreleri çerçevesinde incelenmesi ve meydana gelen değişimlerin raporlanmasıdır.

\section{YÖNTEM}

Araştırma modeli: Bu çalışma, 2002 - 2020 yılları arasında NBA ve EuroLeague normal sezonlarında oynanan müsabakaları değerlendiren, tarama modeli kullanılarak yapılmış bir çalışmadır.

Araştırma grubu: Çalı̧smanın evrenini 2002 - 2020 yıllarında NBA'de oynanan 46.260 ve EuroLeague'de oynanan 8.656 maç oluşturmaktadır. Belirtilen sezonlarda oynanan tüm normal sezon maçları çalışma kapsamın alınmıştır.

Verilerin toplanması: Çalışmada kullanılan veriler, liglerin resmi siteleri olan www.nba.com ve www.EuroLeague.net sayfalarından elde edilmiştir. Açık erişimde sunulan bu bilgiler basketbol ve müsabaka analizi alanında çalışan iki analiz uzmanı tarafından sınıflandırılmıştır. Çalışmada kullanılan veriler basketboldaki temel istatistik kategorilerini kapsamaktadır.

Verilerin analizi: Araştırmada elde edilen veriler, SPSS (IBM SPSS Statistics for Windows, Ver. 22.0 Armonk, NY: IBM Corp.) programı kullanılarak analiz edilmiştir. Veriler değerlendirilirken tanımlayıcı istatistiksel yöntem kullanılmış ve gruplandırılan parametrelerin ortalamaları ve frekans dağılımları tespit edilmiş̧ir. Kullanılan veriler, NBA ve EuroLeague'de 2002-2020 yılları arasındeki müsabakalara ait sayı, ortalama atış denemesi ve ortalama isabetli atış, ortalama üç sayılık atış denemesi ve ortalama isabetli üç sayı, asist, ribaunt, blok, top çalma, top kaybı verileridir.

\section{BULGULAR}

$\mathrm{Bu}$ çalışma, basketbolun oyun yapısında meydana gelen değişimleri incelemek amacıyla yapılmıştır. Bu kapsamda, 2002 - 2020 yılları arasında NBA'de oynanan 46.260 ve EuroLeague'de oynanan 8.656 müsabakaya ait sayı, ortalama atı̧ denemesi ve ortalama isabetli atış, ortalama üç sayılık atış denemesi ve ortalama isabetli üç sayı, asist, ribaunt, blok, top çalma, top kaybı istatistikleri analiz edilmiştir. NBA'de normal sezonda bir takım 82 müsabaka yaparken, 2011 - 2012 sezonundaki lokavt dolayısıyla belirtilen sezonda takımlar 66 maç yapabilmişlerdir. Yapılan analizler sonucunda elde edilen bulgular bu bölümde sunulmuştur. 
Ertetik, G., Durmuş, T., Erdeveciler, Ö. ve Ersöz, G. (2021). Basketbolun değişen yapısı : NBA ve Euroleague örnekleri. Avrasya Spor Bilimleri ve Ĕgitim Dergisi, 3(1), 81-95.

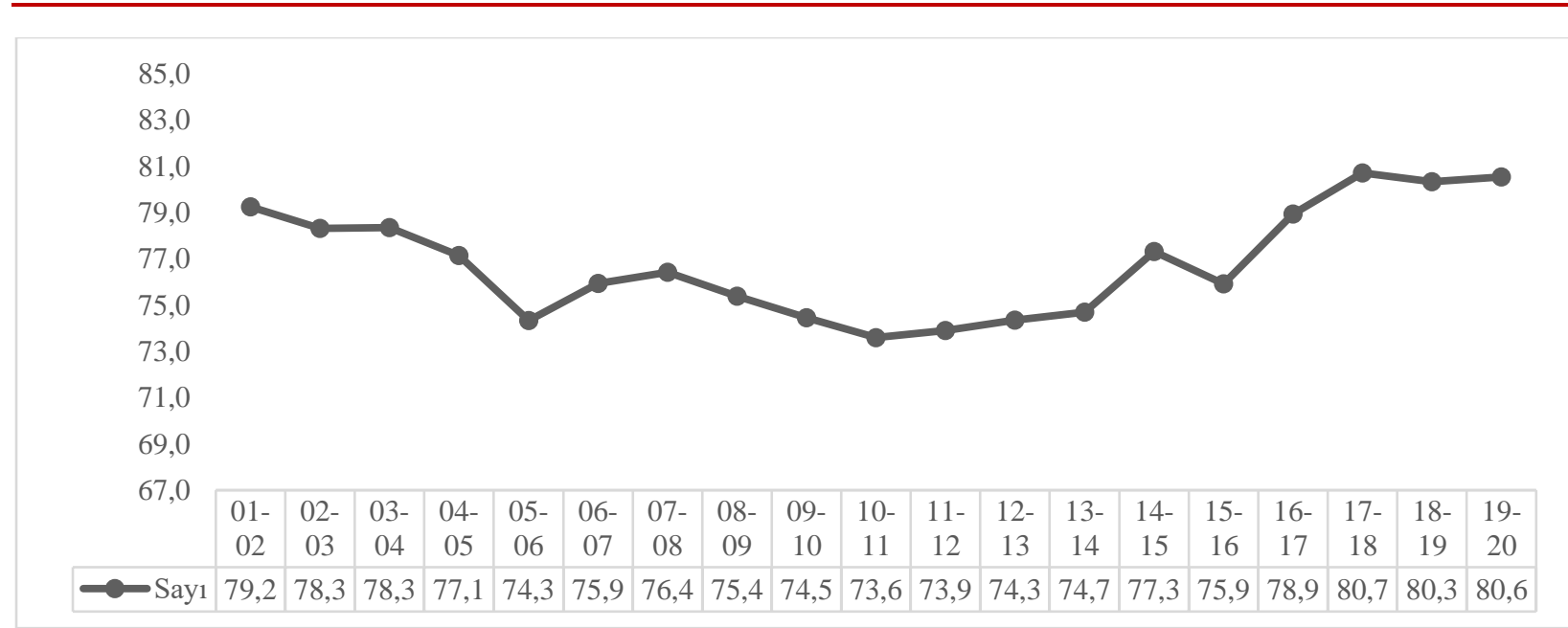

Şekil 1. EuroLeague'de maç başına atılan ortalama sayının sezonlara göre değişimi

Şekil 1'de EuroLeague'de maç başına ortalama sayı rakamlarında meydana gelen değişim gösterilmiştir. EuroLeague'de son on dokuz sezonda en az sayı ortalaması yakalanan sezon 20052006 sezonu olurken, en yüksek sayı ortalaması ise 2017-2018 sezonunda görülmüştür.

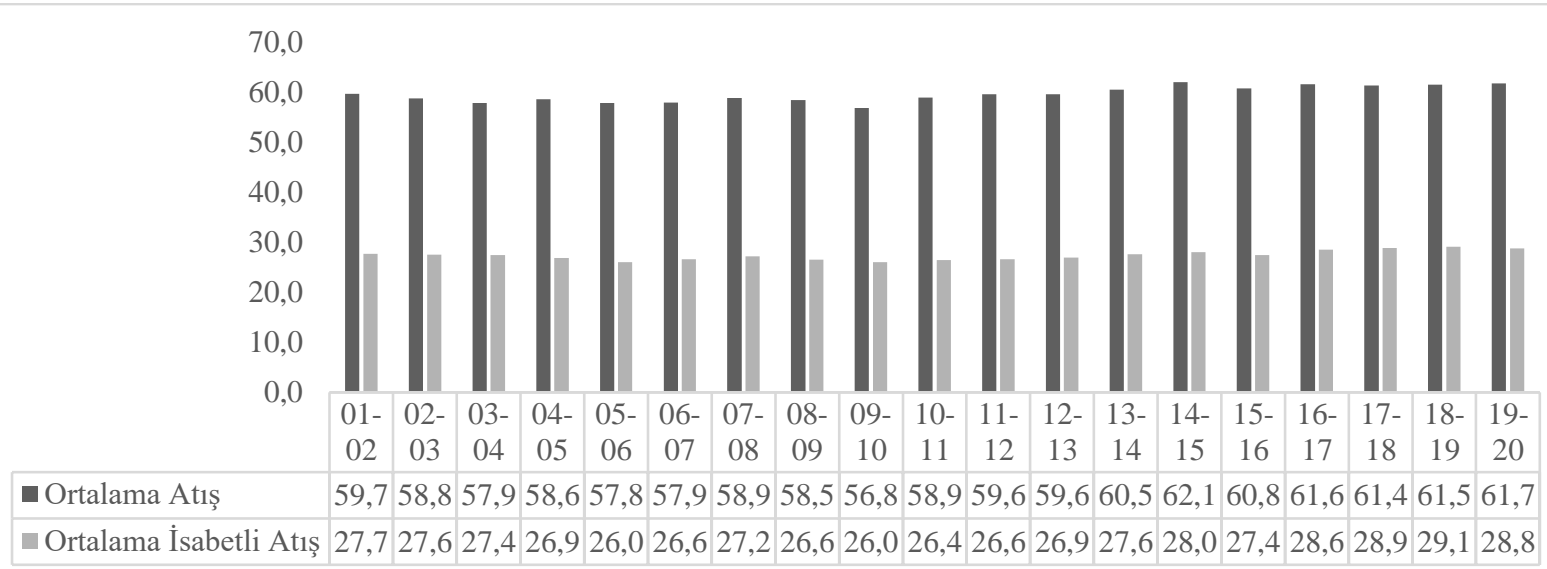

Şekil 2. EuroLeague'de ortalama atış / ortalama isabetli atış oranlarının sezonlara göre değişimi

EuroLeague'de maç başına ortalama atış ve ortalama isabetli atışlardaki değişim Şekil 2'de gösterilmiştir. Toplam oyun süresi ve hücum süresinin aynı olduğu bu sezonlarda maç başına en çok atış kullanılan sezon 2014-2015 sezonu olurken, en çok isabet bulunan sezon ise 2018-2019 sezonu olmuştur. 
Ertetik, G., Durmuş, T., Erdeveciler, Ö. ve Ersöz, G. (2021). Basketbolun değişen yapısı : NBA ve Euroleague örnekleri. Avrasya Spor Bilimleri ve Ĕgitim Dergisi, 3(1), 81-95.

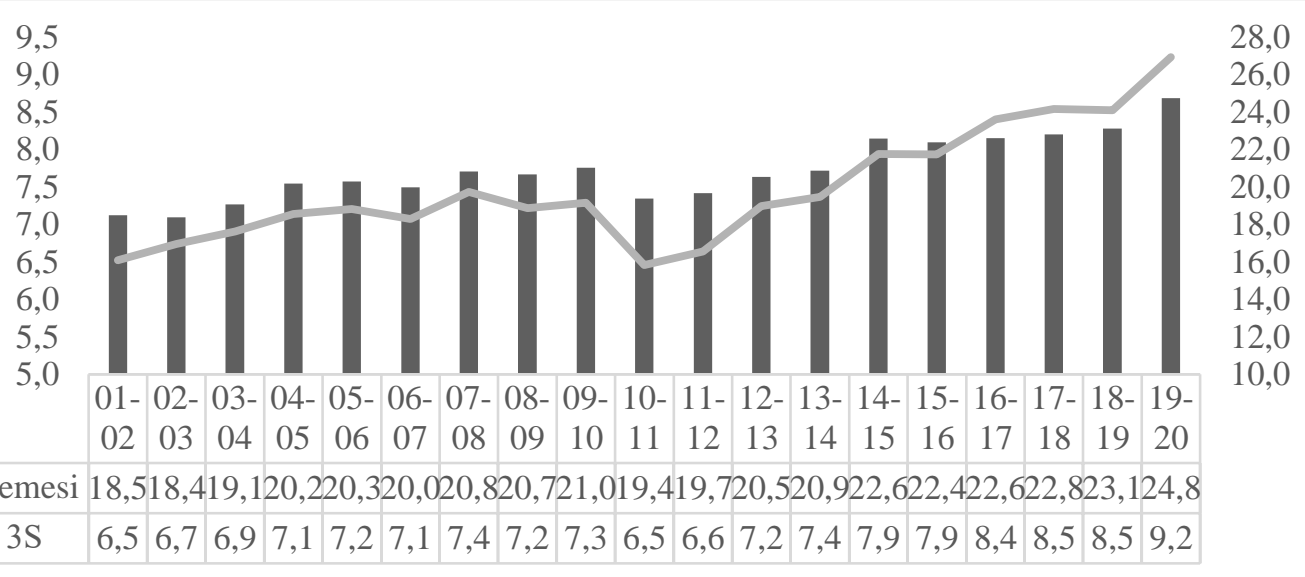

Ort. 3S Denemesi —Ort. İsabetli 3S

Şekil 3. EuroLeague'de ortalama 3 sayılık atış / ortalama 3 sayılık isabetli atış oranlarının sezonlara göre değişimi

EuroLeague'de üç sayılık atışların kullanımındaki değişim Şekil 3'te gösterilmiştir. Üç sayılık atışlar en az 2002-2003 sezonu, en fazla ise 2019-2020 sezonunda kullanılmıştır. Bununla birlikte 2019-2020 sezonunda bulunan maç başına ortalama 9,2 isabetli üç sayı atış, çalışma kapsamındaki yıllar içindeki en yüksek rakamdır. 2002 sezonunda EuroLeague'de üç sayılık atışlar takımların toplam atış oranının \%30,98'ini oluştururken 2020 sezonunun sonuna gelindiğinde hücumlarını sonlandırmak için \%37,46 oranında üç sayılık atış kullanmışlardır.

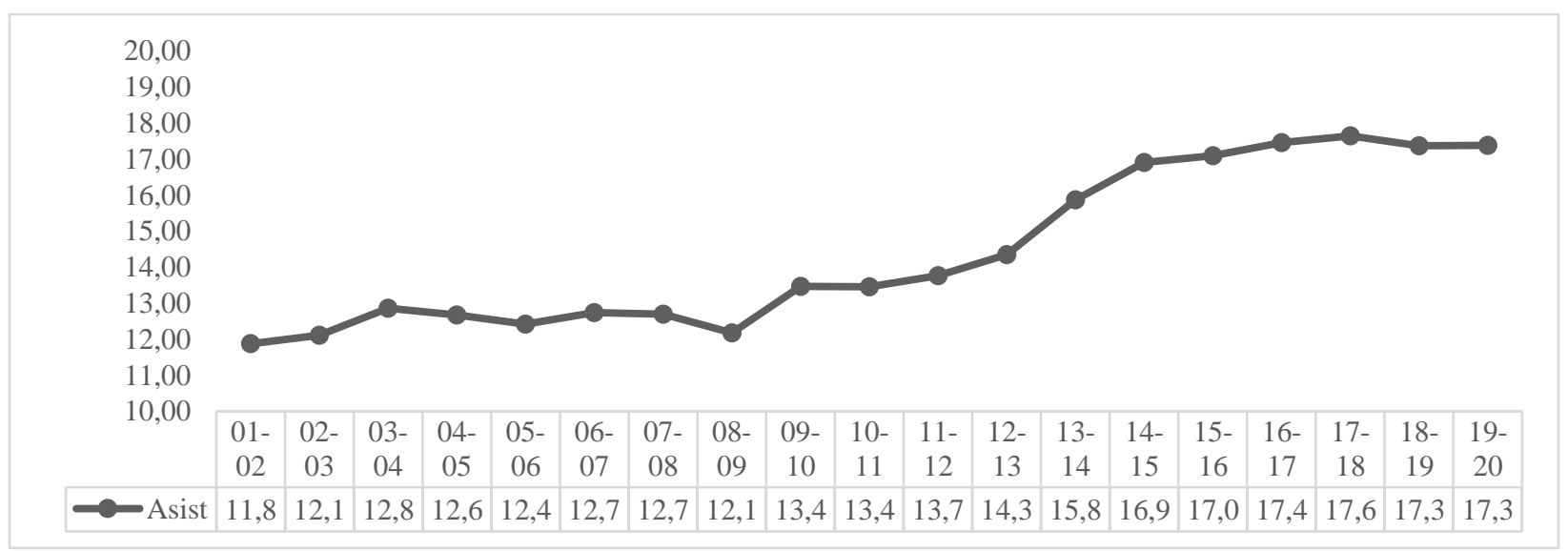

Şekil 4. EuroLeague'de ortalama asist rakalmlarının sezonlara göre değişimimi

Şekil 4, EuroLeague'de asist rakamlarında meydana gelen değişimi göstermektedir. Buna göre EuroLeague'de, 2008-2009 sezonundan itibaren asist rakamlarının geçen her sezonda artış gösterdiği belirlenmiştir. 
Ertetik, G., Durmuş, T., Erdeveciler, Ö. ve Ersöz, G. (2021). Basketbolun değişen yapısı : NBA ve Euroleague örnekleri. Avrasya Spor Bilimleri ve Ĕgitim Dergisi, 3(1), 81-95.

Yapılan analizler sonucunda NBA'de istatistiksel kategorilerde meydana gelen değişimler aşağıdaki şekillerde gösterilmiştir.

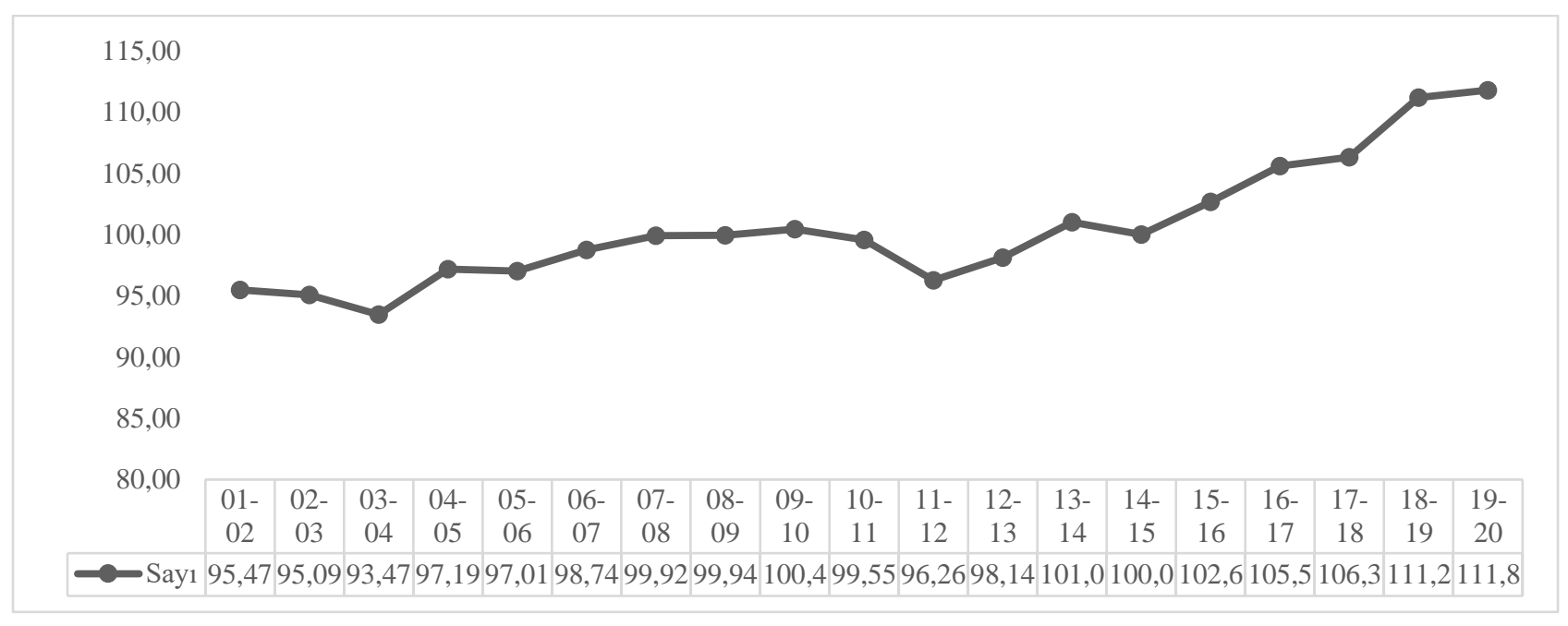

Şekil 5. NBA'de maç başına atılan ortalama sayının sezonlara göre değişimi

NBA'de maç başına atılan sayıların değişimi Şekil 5'te sunulmuştur. NBA'de, 2001-2002 sezonunda 95,4 olan sayı ortalamasının 2019-2020 sezonunda 111,8 sayıya ulaştığı görülmüştür.

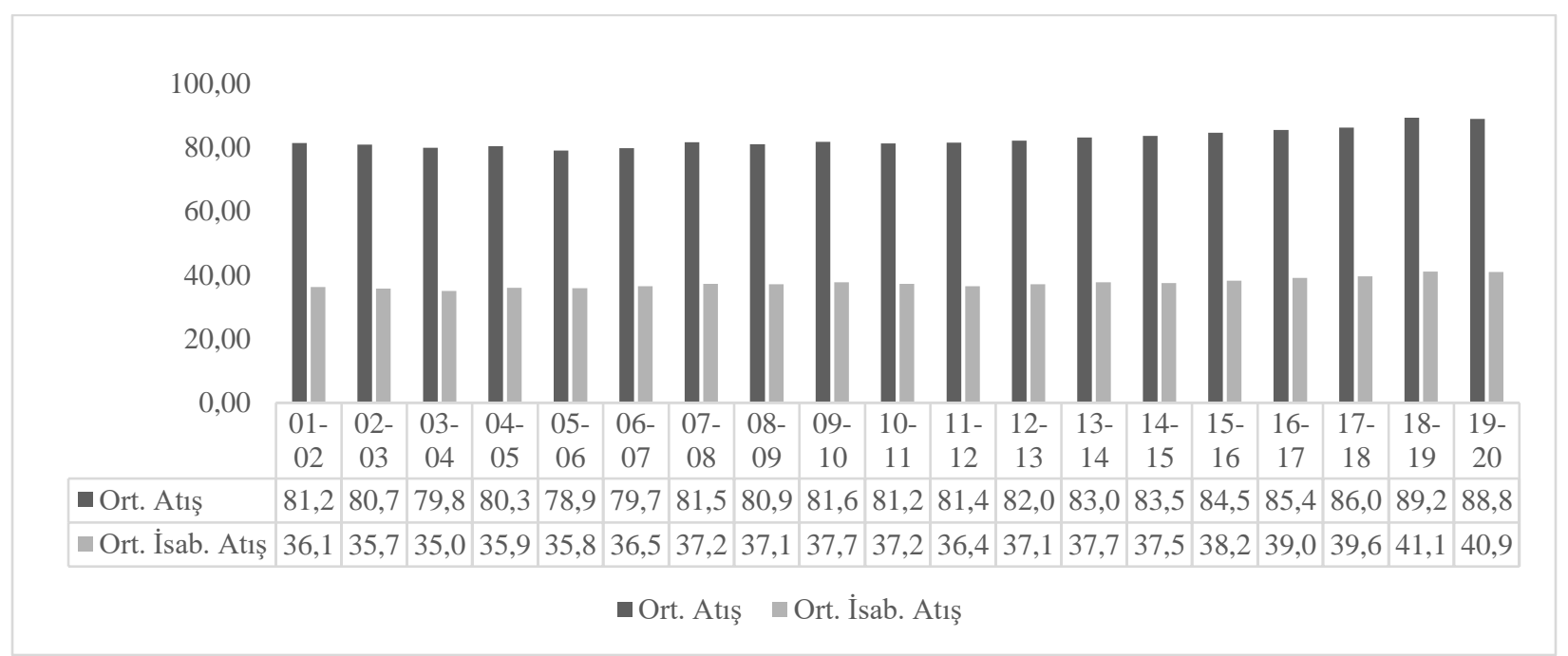

Şekil 6. NBA'de ortalama atış / ortalama isabetli atış oranlarının sezonlara göre değişimi

Şekil 6, NBA'de maç başına kullanılan atış ve isabetli atışların dağılımını göstermektedir. 20012002 sezonunda 48 dakikalık bir maçta takımlar ortalama 81,2 atış kullanırken 2019-2020 sezonunda aynı oyun süresinde takımlar 88,8 atış kullanmıştır. 
Ertetik, G., Durmuş, T., Erdeveciler, Ö. ve Ersöz, G. (2021). Basketbolun değişen yapısı : NBA ve Euroleague örnekleri. Avrasya Spor Bilimleri ve Ĕgitim Dergisi, 3(1), 81-95.

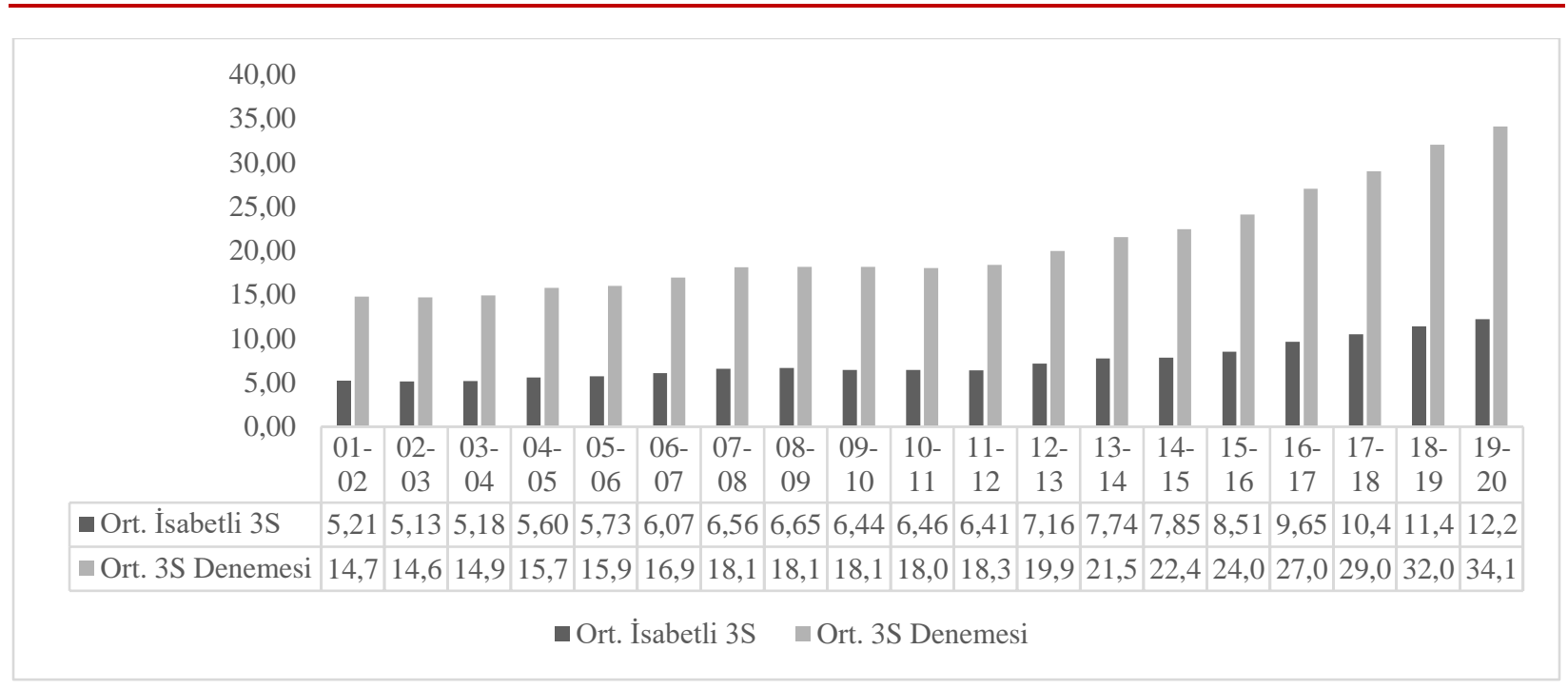

Şekil 7. NBA'de ortalama 3 sayılık atı̧s / ortalama 3 sayılık isabetli atış oranlarının sezonlara göre değişimi

NBA'de üç sayılık atışların sayısı ve isabeti Şekil 7'de sunulmuştur. Buna göre, NBA'de 20012002 sezonunda maç başına kullanılan ortalama 14,7 üç sayılık atıştan 5,2'si isabetli olurken bu oran 2019-2020 sezonunda 34,1 ortalama atış ve 12,2 isabetli atış olarak değişim göstermiştir.

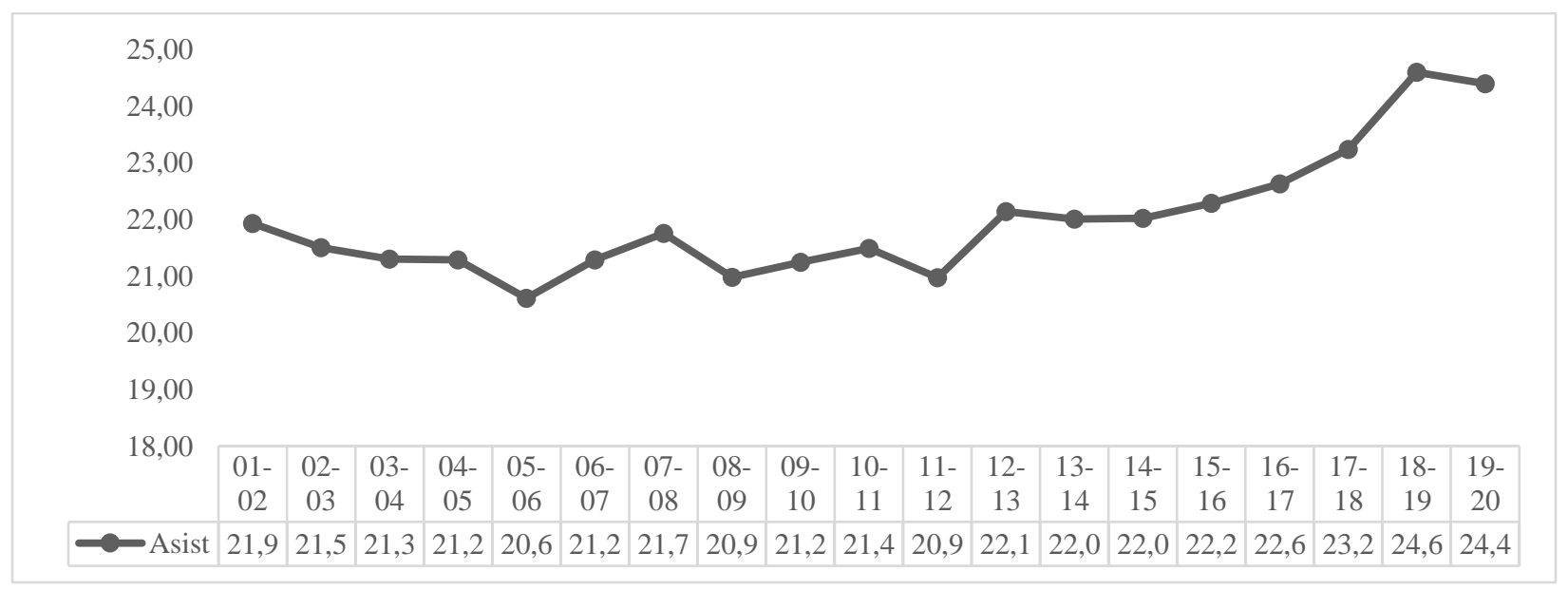

Şekil 8. NBA'de ortalama asist rakamlarının sezonlara göre değişimi

Şekil 8, NBA'de 2001-2002 ve 2019-2020 sezonları arasında asist rakamlarında meydana gelen değişimi göstermektedir. Çalışma kapsamındaki yıllarda en düşük asist yapılan sezon 2005-2006 sezonuyken, asist ortalamasının en yüksek olduğu sezonun 2019-2020 sezonu olduğu saptanmıştır. 

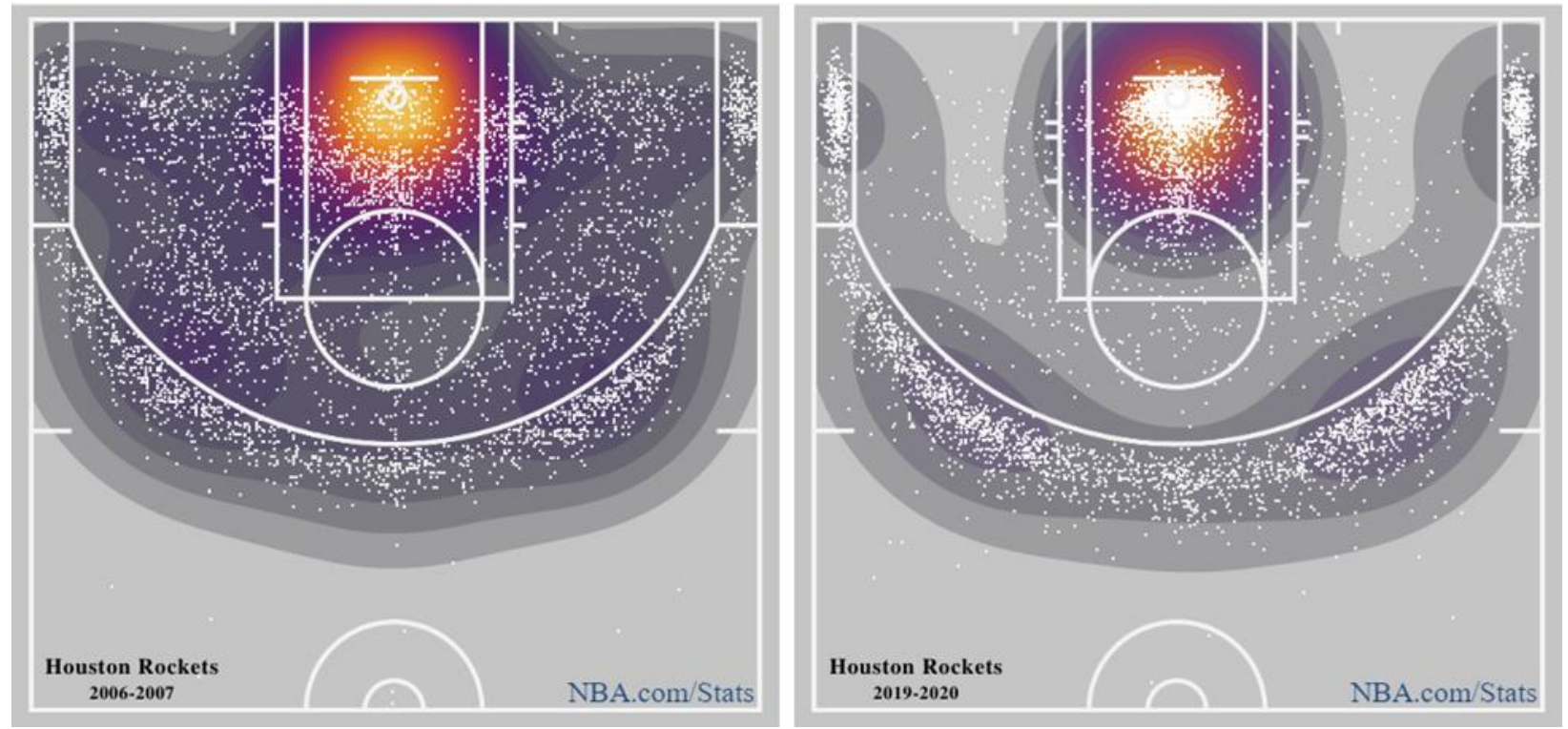

Şekil 9. NBA takımlarından Houston Rockets'ın 2007 ve 2020 yıllarındaki şut tercihleri

Şekil 9, NBA takımlarından Houston Rockets'ın 2006-2007 ve 2019-2020 sezonlarındaki ağırlıklı olarak atış kullandığı bölgelerin ısı haritasıdır. Şekillerde giderek koyulaşan gri alanlar en çok atış kullanılan bölgeleri temsil etmektedir. Şekil 9'dan yola çıkılarak Houston Rockets'ın 2006-2007 sezonunda üçlük çizgisi ve çember arasındaki bölgeden kullandığı atışlardaki yoğunluğun, 20192020 sezonunda çember altı ve üçlük çizgisinin dişında yoğunlaştığı söylenebilir.

\section{TARTIŞMA VE SONUÇ}

Bu çalışmanın amacı, NBA ve EuroLeague'de ortalama atış denemesi ve ortalama isabetli atış, ortalama üç sayılık atış denemesi ve ortalama isabetli üç sayı, asist, ribaunt, blok, top çalma, top kaybı istatistiklerinin değişimini incelemektir. Bu kapsamda, 2002 - 2020 yılları arasında NBA'de oynanan 46.260 ve EuroLeague'de oynanan 8.656 müsabakaya ait veriler çalışma kapsamında analiz edilmiştir.

Yapılan analizler sonucunda; EuroLeague ve NBA'de sezonlar ilerledikçe en çarpıcı değişimlerin maç başına yapılan sayı denemesi, atılan sayı, maç başına toplam üç sayılık atış denemesi ve isabetli üç sayılık atışlarda meydana geldiği tespit edilmiştir. EuroLeague'de 2010-2011 sezonunda bir takım maç başına 73,6 sayı atarken bu rakam 2019-2020 sezonunda 80,6 sayıya yükselmiştir. Bu değişim, NBA'de daha etkili biçimde meydana gelmiştir. 2001-2002 sezonunda maç başına ortalama sayı 95,5 sayı iken bu rakam 2019-2020 sezonunun sonunda 111,8 sayıya kadar yükselmiştir. Bu alanda 19 sezonda \%17,1 oranında bir artış görülmüştür. Her iki ligde de maç başına kullanılan atış denemelerinde de artışlar meydana gelmiştir. Nitekim NBA'de 19 sezonun ardından takımlar maç başına 7,8 $(\% 9,3)$ fazla atış kullanmışlardır. Oyun süresinin 
Ertetik, G., Durmuş, T., Erdeveciler, Ö. ve Ersöz, G. (2021). Basketbolun değişen yapısı : NBA ve Euroleague örnekleri. Avrasya Spor Bilimleri ve Ĕgitim Dergisi, 3(1), 81-95.

değişmemesi, kuralların oyunun oynanış biçiminde köklü değişiklikler meydana getirmemesi ve sezonların birbirini takiben oynanması düşünüldüğünde bu değişimlerin oyunun teknik - taktik boyutundan ve genel olarak oynanış biçiminden kaynaklandığı söylenebilir (Mikołajec vd., 2021; Selmanović vd., 2015; Strumbelj vd., 2013).

Çalışma kapsamında ele alınan istatistiksel kategorilerdeki en büyük değişimler üç sayılık atış denemesi ve üç sayılık isabetli atış oranlarında meydana gelmiştir. Buna göre; EuroLeague'de takımlar 2001-2002 sezonunu maç başına 18,5 üç sayılık atış denemesi ile kapatırken 2020 sezonunun sonunda bu rakam 24,8 olarak yansımıştır. İsabetli atış oranındaki değişim de aynı doğrultuda 6,5'den 9,2'ye yükselmiştir. NBA'de de 2002 sezonu sona erdiğinde takımlar sadece 14,7 üç sayılık atış denemesi yapmışlardır. Ancak bu sayı 2020 sezonunun sonunda \%131 oranında bir değişime uğrayarak 34,1'e ulaşmıştır. 2001 yılında bu atışlardan 5,1'i isabetli olurken 2020 y1lında ise takımlar maç başına ortalama 12,2 üç sayı isabeti bulmuşlardır. 2001-. NBA'de ise 2002 sezonu sonunda takımların üç sayllık denemelerinin toplam atış denemelerine oranı \%18,16'da kalmıştır. Buna karşılık olarak, 2019-2020 sezonunda NBA takımları hücumlarının \%38,40'ını üç sayılık atışlar ile sonlandırmışlardır. EuroLeague ve NBA'de oyunun değişimini en açık şekilde simgeleyen üç sayılık atışların kullanım oranları ve isabet yüzdeleri üzerine birçok çalışma literatürde mevcuttur (Erčulj ve Štrumbelj, 2015; Petway vd., 2020; Mandić vd., 2019). NBA'de 2010 sezonu ve öncesindeki üç sayılık atış denemelerindeki oranın düşüklügü oyun taktik ve yaklaşımının uzun oyuncular etrafında şekillenmesiyle ve boyalı alanın daha fazla kullanılmasıyla da ilişkilendirilebilir (Piette vd., 2010).

Zhang'a (2020) göre takımlar skor avantajı elde etmek amacıyla çok sayıda uzun ikilik atışlar denemek yerine daha az sayıda üç sayılık atışlara yönelmiş̧lerdir. Rust (2014) ise NBA'de en çok değer verilen şutun köşeden atılan üç sayılar olduğunu; uzun ikiliklerin isabet oranlarının boyalı alan sayılarından düşük olması sebebiyle birkaç adım geriden atılacak üç sayının skora etkisini vurgulamıştır. Rust (2014) aynı zamanda bu yönelimlerin, takımların oyuncu tercihleri ve kadro planlamalarında da etkili olduğunu belirtmiştir.

Atış denemelerindeki yükseliş ile birlikte ribaunt sayılarında muhtemel bir artış beklenebilir. Ancak isabetli şut oranlarının da aynı doğrultuda yükselmesi ile birlikte bu artışın istatistiksel olarak yüksek oranlarda olmadığını söylemek mümkündür. Geleneksel istatistiklerde meydana gelen yükseliş, oyunun oynanma hızının artması ile ilişkilendirilebilir (Cadenas ve Ibáñez, 2017; Çene, 2018; Kubatko vd., 2007; Selmanović vd., 2015).

Oyunun hızlanması ile hücum sürelerinin kısalması, erken atışların kullanılması ve bu atışların isabet oranlarının artmasının savunma istatistikleri ile ters orantılı olduğu söylenebilir. Rakip savunmalar doğru ve etkili şekilde yerleşmeden kullanılan atışların etkisini top çalma ve blok rakamlarında azalma olarak görmek mümkündür. EuroLeague'de 2002 sezonunda 7,8 olan ortalama top çalma rakamı 2020 sezonunda 6,5'e; NBA'de 7,8'den 7,6'ya gerilemiştir. Bununla birlikte maç başına yapılan bloklardaki değişim ise sadece $\% 5$ 'tir. Hücum eden takımların rakip 
savunma henüz yerleşmemişken yaptıkları erken ve isabetli atışların etkisi top kaybı rakamlarında da ortaya çıkmıştır. Savunma baskısı artmadan, hücum süresinin başlarında yapılan isabetli atışlar sayesinde top kaybı riskinin azaltıldığını söylemek mümkündür. Ibáñez vd., (2008) İspanya Basketbol Ligi'nde takımların sezon başarılarında assist, top çalma ve blok istatistiklerinin etkisinin daha fazla olduğunu belirtmişlerdir. EuroLeague'de 2002 sezonunda hücum eden takımlar maç başına 14,1 top kaybı yaparken 2019 sezonunda sadece 11,8 top kaybı görülmüştür. Bu düşüşün; sayı, üç sayı isabeti ve asist gibi hücum istatistiklerinin artışı ile sonuçlandığı yorumu yapılabilir.

EuroLeague ve NBA, dünyanın en prestijli basketbol organizasyonları olarak kabul edilmektedirler. Yapılan çalışma sonucunda EuroLeague ve NBA'de öncelikle atış denemesi, sayı, üç sayı ve asist rakamlarında sezonlar ilerledikçe meydana gelen bir artıştan söz etmek mümkündür. Bununla birlikte oyun hızının artması ve hücumların erken atışlarla sonlandırılmasından kaynaklı olarak diğer kategorilerde meydana gelen artışın top kaybı rakamlarında aynı oranda olmadığı görülmektedir. Her iki ligi de farklı parametreler ve istatistiksel yöntemlerle incelemiş olan birçok çalışma literatürde mevcuttur. Ancak oyun içerisinde meydana gelen sürekli değişim ve gelişim göz önüne alındığında yapılan çalışmaların güncellenmesi ve farklı istatistiksel yöntemler/yaklaşımlar kullanılarak her iki ligin de analiz edilmesine ihtiyaç duyulmaktadır. Bu çalışma, sadece temel istatistik parametreleri kullanıldığından sınırlı sayıda bileşenin oyun üzerindeki etkilerine odaklanmıştır. Daha sonra yapılacak çalışmalarda gelişmiş istatistiksel parametreler kullanılarak oyunun farklı boyutları ele alınabilir.

Çıkar Çatışması: Bu çalışma ile ilgili olarak yazarların ve/veya aile bireylerinin çıkar çatışması potansiyeli olabilecek bilimsel ve tıbbi komite üyeliği veya üyeleri ile ilişkisi, danışmanlık, bilirkişilik, herhangi bir firmada çalışma durumu, hissedarlık ve benzer durumları yoktur.

Yayın Etiği: Mevcut çalı̧̧manın yazım sürecinde "Yükseköğretim Kurumları Bilimsel Araştırma ve Yayın Etiği Yönergesi" kapsamında bilimsel, etik ve alıntı kurallarına uyulmuş olup; toplanan veriler üzerinde herhangi bir tahrifat yapılmamış ve bu çalışma herhangi başka bir akademik yayın ortamına değerlendirme için gönderilmemiştir.

Yazar Katkı Oranı Beyanı: Göktuğ Ertetik: Verilerin toplanması, verilerin analizi, makale yazımı. Tugay Durmuş: Verilerin toplanması, verilerin analizi, makale yazımı. Övünç Erdeveciler: Makale yazımı. Gülfem Ersöz: Çalışmanın kavramsal çerçevesinin düzenlenmesi ve çalışmanın editi edilmesi. 
Ertetik, G., Durmuş, T., Erdeveciler, Ö. ve Ersöz, G. (2021). Basketbolun değişen yapısı : NBA ve Euroleague örnekleri. Avrasya Spor Bilimleri ve Ĕgitim Dergisi, 3(1), 81-95.

\section{KAYNAKÇA}

Arias, J. L., Argudo, F. M. \& Alonso, J. I. (2009). Effect of the 3-point line change on the game dynamics in girls' minibasketball. Research quarterly for exercise and sport, 80(3), 502-509.

Courel-Ibáñez, J., McRobert, A. P., Ortega, E. \& Cárdenas Vélez, D. (2018). Inside game effectiveness in NBA basketball: Analysis of collective interactions. Kinesiology, 50(2), 218-227. Doi:10.26582/k.50.2.5.

Çene, E. (2018). What is the difference between a winning and a losing team: Insights from EuroLeague basketball. International Journal of Performance Analysis in Sport, 18(1), 55-68. Doi:10.1080/24748668.2018.1446234.

Dean, O. (2001). Statistical effects of proposed NBA rule changes. Journal of Basketball Studies. [Available online at: http://www.rawbw.com/ deano/articles/2001_rule_chg_discussion.htm], Erişim tarihi: 10 Mart 2021.

Drust, B. (2010). Performance analysis research: meeting the challenge. Journal of Sports Sciences, 28(9), 921-922. Doi:10.1080/02640411003740769.

Erčulj, F. \& Štrumbelj, E. (2015). Basketball shot types and shot success in different levels of competitive basketball. PloS One, 10(6). e0128885. Doi: 10.1371/journal.pone.0128885.

EuroLeague. (2021). EuroLeague Statistics https://www.euroleague.net/main/statistics Erişim tarihi: 13 Şubat 2021.

Fichman, M. \& O'Brien, J. (2017). Three point shooting and efficient mixed strategies: A portfolio management approach. Journal of Sports Analytics, 4(2), 1-14. Doi: 10.3233/JSA-160154.

Franks, I. \& Hughes, M. (2007). The Essentials of Performance Analysis: An Introduction (1st ed.). USA: Routledge.

Ibáñez, S., Sampaio, J., Feu, S., Lorenzo, A., Gómez, M. \& Ortega, E. (2008). Basketball game-related statistics that discriminate between teams' season-long success. European Journal of Sport Science, 8(6), 369-372. Doi: 17461390802261470 .

Karipidis, A., Fotinakis, P., Taxildaris, K. \& Fatouros, J. (2001). Factors characterizing a successful performance in basketball. Journal of Human Movement Studies, 41(5), 385-397.

Kubatko, J., Oliver, D., Pelton, K. \& Rosenbaum, D. T. (2007). A starting point for analyzing basketball statistics. Journal of Quantitative Analysis in Sports, 3(3), 1-24. Doi: 10.2202/1559-0410.1070.

Mandić, R., Jakovljević, S., Erčulj, F. \& Štrumbelj, E. (2019). Trends in NBA and EuroLeague basketball: Analysis and comparison of statistical data from 2000 to 2017. PloS one, 14(10), e0223524. Doi: journal.pone.0223524.

Mateus, N., Gonçalves, B., Abade, E., Leite, N., Gomez, M. A. \& Sampaio, J. (2018). Exploring game performance in NBA playoffs. Kinesiology, 50(1), 89-96. Doi: 10.26582/k.50.1.7.

Mavridis, G., Evangelos, T., Alexandros, K. \& Laios, A. (2009). The inside game in world basketball. Comparison between European and NBA teams. International Journal of Performance Analysis in Sport, 9(2), 157-164. Doi: 10.1080/24748668.2009.11868473.

Mikołajec, K., Banyś, D., Żurowska-Cegielska, J., Zawartka, M. \& Gryko, K. (2021). How to win the basketball EuroLeague? Game performance determining sports results during 2003-2016 matches. Journal of Human Kinetics, 77(1), 287-296. Doi: 10.2478/hukin-2021-0050. 
Ertetik, G., Durmuş, T., Erdeveciler, Ö. ve Ersöz, G. (2021). Basketbolun değişen yapısı : NBA ve Euroleague örnekleri. Avrasya Spor Bilimleri ve Eğitim Dergisi, 3(1), 81-95.

NBA. (2021). Official NBA Stats. https://www.nba.com/stats/teams/traditional Erişim tarihi: 10 Şubat 2021.

Nourayi, M. M. (2019). Strategically driven rule changes in NBA: Causes and consequences. The Sport Journal, 22, $1-11$.

Paulauskas, R., Masiulis, N., Vaquera, A., Figueira, B. \& Sampaio, J. (2018). Basketball game-related statistics that discriminate between European players competing in the NBA and in the Euroleague. Journal of Human Kinetics, 65, 225-233. Doi: 10.2478/hukin-2018-0030.

Petway, A. J., Freitas, T. T., Calleja-González, J., Medina Leal, D. \& Alcaraz, P. E. (2020). Training load and matchplay demands in basketball based on competition level: A systematic review. PloS one, 15(3), e0229212. Doi: 10.1371/journal.pone.0229212.

Piette, J., Anand, S. \& Zhang, K. (2010). Scoring and shooting abilities of NBA players. Journal of Quantitative Analysis In Sports, 6(1). Doi: 10.2202/1559-0410.1194.

Rust, D. (2014). An Analysis of New Performance Metrics in the NBA and Their Effects on Win Production and Salary. Yayımlanmamış bitirme tezi, University of Mississippi, Sally McDonnell Barksdale Honors College, USA.

Sampaio, J. \& Janeira, M. (2003). Statistical analyses of basketball team performance: Understanding teams' wins and losses according to a different index of ball possessions. International Journal of Performance Analysis in Sport. 3. 40-49. Doi: 10.1080/24748668.2003.11868273.

Scanlan, A. T., Wen, N., Spiteri, T., Milanović, Z., Conte, D., Guy, J. H., Delextrat, A. \& Dalbo, V. J. (2018). Dribble deficit: A novel method to measure dribbling speed independent of sprinting speed in basketball players. Journal of Sports Sciences, 36(22), 2596-2602. Doi: 10.1080/02640414.2018.1470217

Selmanović, A., Škegro, D. \& Milanović, D. (2015). Basic characteristics of offensive modalities in the EuroLeague and the NBA. Acta Kinesiologica, 9(2), 83-87.

Strumbelj, E., Vračar, P., Robnik-Šikonja, M., Dežman, B. \& Erčulj, F. (2013). A decade of EuroLeague basketball: an analysis of trends and recent rule change effects. Journal of Human Kinetics, 38, 183-189. Doi: 10.2478/hukin-2013-0058

Suárez-Cadenas, E. \& Courel-Ibáñez, J. (2017). Shooting strategies and effectiveness after offensive rebound and its impact on game result in EuroLeague basketball teams. Cuadernos de Psicología del Deporte, 17(3), 217222.

Zhuang, F. (2020). NBA three point shot attempts and accuracy distribution. Scientific and Social Research, 2(2). Doi:10.36922/ssr.v2i2.947 
Ertetik, G., Durmuş, T., Erdeveciler, Ö. ve Ersöz, G. (2021). Basketbolun değişen yapısı : NBA ve Euroleague örnekleri. Avrasya Spor Bilimleri ve Eğitim Dergisi, 3(1), 81-95.

\section{EXTENDED ABSTRACT}

\section{The Changing Game Structure of Basketball: Examples of NBA and EuroLeague}

\section{Introduction}

Basketball is one of the most widespread sports globally, and with this, two organizations stand out in the world: NBA (National Basketball Association) and EuroLeague (Europa League). Performance analysis in team sports has gradually accelerated in the last decade, with the ease of accessing data regarding the training and competition process. There are studies about the changing game structure of basketball and the effects of some parameters on the playing style of basketball. The deepest change in the history of NBA basketball is the inclusion of the 3-point shot. Yet, the effect of the change was not immediately apparent, but this change affects game strategies even today. In some studies on European basketball, it is stated that the performance of teams depends primarily on 2-point shots and defensive rebounds. In a study comparing the attacking styles of NBA and EuroLeague teams, it was stated that the most obvious feature that distinguishes NBA teams from EuroLeague teams is the offense of the painted area.

\section{Method}

This research aims to determine several statistical parameters to assess changes in the game's structure. This study includes games played in National Basketball Association (NBA) and European Basketball League (EuroLeague) regular seasons between 2002 and 2020. The points per game, shot attempts/made, three-point attempts/made, rebounds, assists, steals, turnovers, and block averages of the teams have all been grouped and analyzed. Since there are differences between the two leagues in terms of game time and game rules, the change and comparison of these parameters over the years have been made separately for the two leagues. Only two basketball leagues (NBA and EuroLeague) were evaluated in this study. However, the study is limited to the regular season matches of these two leagues.

\section{Findings}

As a result of the analysis, it was found that the most significant changes occurred in the number of shots made per game, the points scored, the average three-point shot attempts per game, and the successful three-point shot attempts as the seasons progressed in the EuroLeague and NBA. The biggest changes in the statistical categories considered within the scope of the study occurred in the three-point attempts and the three-point shooting rate. This change has occurred more effectively in the NBA. While the average points per game was 95.5 points in the 2001-2002 season, this number increased to 111.8 points at the end of the 2019-2020 season. With the increase in shot attempts, a possible increase in rebound numbers can be expected. However, it is possible to say that this increase is not at a statistically high rate, with the accuracy of shot attempts also increasing in the same direction. 
Ertetik, G., Durmuş, T., Erdeveciler, Ö. ve Ersöz, G. (2021). Basketbolun değişen yapısı : NBA ve Euroleague örnekleri. Avrasya Spor Bilimleri ve Eğitim Dergisi, 3(1), 81-95.

\section{Discussion and Conclusion}

According to the results of this study, it is possible to talk about an increase in the number of shot attempts, points, three points and assists in the EuroLeague and NBA as the seasons progress. There are many studies in the literature that have examined both leagues with different parameters and statistical methods. However, considering the continuous changes and developments occurring in the game, it is necessary to update the studies and analyze both leagues by using different statistical methods/approaches.

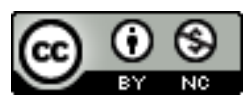

Bu eser Creative Commons Atıf-Gayri Ticari 4.0 Uluslararası Lisansı ile lisanslanmıştır. 